\title{
Democracia e capital social no Rio Grande do Sul
}

\author{
Everton Santos* \\ Valdir Pedde** \\ Simone Viscarra*** \\ Cíntia Ventura***
}

\section{Introdução}

\begin{abstract}
A década de 1980 é caracterizada por um importante fenômeno de mudança no regime político brasileiro, pois transitamos de um regime autoritário, "não-democrático", para uma forma de governo "democrática”. Esta mudança, por sua vez, foi acompanhada de uma tarefa bastante complexa para a comunidade acadêmica, à medida em que tornava-se necessário não somente explicar o fenômeno em curso, bem como suas particularidades, num país que acabava de enfrentar um regime político dirigido pelo poder militar.

Como veremos, inúmeros analistas estudaram o fenômeno da democracia, ora colocando ênfase na modernização da sociedade, ora colocando acento na escolha dos atores; com o propósito
\end{abstract}

* Graduado em Ciências Sociais. Mestre e Doutor em Ciência Política pela UFRGS, atualmente é Professor Titular no Centro Universitário FEEVALE, onde atua como coordenador do Mestrado em Inclusão Social e Acessibilidade e pesquisador no Grupo de Estudos em Desenvolvimento Regional. É Professor Adjunto na ULBRA no curso de Graduação em Ciência Política e na Pós-Graduação. Endereço eletrônico: evertons@feevale.br

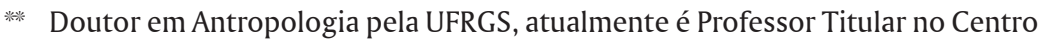
Universitário FEEVALE e pesquisador no Grupo de Estudos em Desenvolvimento Regional. Endereço eletrônico: valpe@feevale.br

**** Graduada em Ciências Sociais pela UFRGS e mestranda no Programa de PósGraduação em Ciência Política da UFRGS. Endereço eletrônico: simoneviscarra@ gmail.com

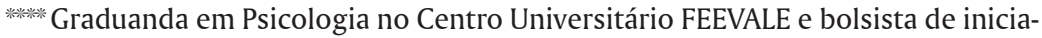
ção científica no Grupo de Estudos em Desenvolvimento Regional. Endereço eletrônico: cintiavvs@gmail.com 
de encontrar nexos explicativos que dessem conta de explicar sua emergência e sua estabilidade enquanto regime político. A partir de uma revisão teórica da literatura pertinente a respeito do tema, o presente artigo, debruçando-se sobre duas regiões do estado do Rio Grande do Sul/Brasil: região do Vale do Rio dos Sinos ${ }^{1}$ e região Nordeste $^{2}$, objetiva analisar as condições societais que favorecem a democracia na região, articulando o conceito de democracia com o conceito de capital social na tradição de Putnam (2000).

Dentro do contexto apresentado, nossa hipótese parte do pressuposto que existe uma forte associação entre capital social e democracia. Assim, buscamos defender a idéia de que a existência de estoques de capital social, por meio de indicadores como a confiança interpessoal e institucional (trust) em uma determinada sociedade influencia positivamente a crença no regime democrático e em suas instituições. Em outras palavras, a democracia é favorecida pelo capital social.

Objetivando demonstrar nosso argumento, dividimos este artigo em três tópicos. No primeiro, "As Possibilidades da Democracia", apresentaremos, de maneira sucinta, uma discussão teórica que procura explicar como a democracia pode florescer enquanto regime político, de uma maneira geral. O tópico tem como propósito mostrar o argumento de uma vertente teórica nas Ciências Sociais que acredita ser a democracia fruto da modernização da sociedade, ou seja, de que a mudança nas condições sociais e econômicas da sociedade é o principal fator gerador de sociedades democráticas (de acordo com os teóricos da modernização), para, em seguida, apresentarmos um argumento contrário ao primeiro (foco nos atores políticos), segundo o qual a democracia seria fruto da escolha racional de lideranças políticas que tornam a democracia possível.

1 Cidades do Corede (Conselho Regional de Desenolvimento) Vale do Rio dos Sinos: Campo Bom, Canoas, Dois Irmãos, Estância Velha, Esteio, Ivoti, Novo Hamburgo, Portão, São Leopoldo, Sapiranga e Sapucaia do Sul.

2 Cidades do Corede Nordeste:Água Santa, André da Rocha, Barracão, Cacique Doble, Capão Bonito do Sul, Caseiros, Esmeralda, Ibiaçá, Ibirairas, Lagoa Vermelha, Machadinho, Maximiliano de Almeida, Muitos Capões, Paim Filho, Pinhal da Serra, Sananduva, Santo Expedito do Sul, Santa Cecília, São João da Urtiga, São José do Ouro, Tapejara, Tupanci do Sul e Vila Lângaro. 
Demonstraremos que as formulações feitas pelos teóricos dos atores políticos não se concretizaram, pelo contrário, produziram uma frustração teórica à medida que, de uma maneira geral, a democracia social e a prosperidade social propalada por estes não se efetivaram. Assim, apresentamos a retomada das análises que apostam na modernização, porém, com um enfoque novo, para que possamos compreender as possibilidades da democracia. Neste sentido, a riqueza econômica não seria a responsável direta pela promoção da democracia, entretanto, a sua permanência, em longo prazo, explicaria o fenômeno democrático.

No segundo tópico, "Um Modelo Alternativo para compreender-se a democracia: Capital Social”, propomos um modelo mais abrangente, que explique a emergência da democracia tendo em conta não somente a dimensão da escolha das lideranças políticas, as reformulações das instituições e das leis, que são importantes e necessárias numa sociedade que almeja a democracia (a tese dos minimalistas), como também a necessidade de condições sociais, econômicas, mas principalmente culturais, para que a democracia possa prosperar (a tese dos maximalistas). Portanto, a democracia precisa de crenças e valores que desenvolva uma cultura política cidadã de apoio normativo ao regime democrático. Nesta perspectiva, o conceito de "capital social" torna-se imprescindível para compreendermos a afirmação da democracia, à medida que, quanto maior o volume de indicadores de "capital social" numa dada sociedade, maiores são as possibilidades de a democracia prosperar.

Desta forma, no último tópico, "Democracia e Capital Social”, analisamos os dados de duas regiões brasileiras no estado do Rio Grande do Sul: o Corede Vale do Rio dos Sinos e o Corede Nordeste, no que diz respeito à associação existente entre democracia e capital social, a partir de pesquisa quantitativa tipo survey aplicada nestas respectivas regiões. No Vale dos $\operatorname{Sinos}^{3}$, foram aplicadas 600 entre-

3 Dados referentes à pesquisa do Grupo de Pesquisa em Desenvolvimento Regional CPP/Feevale-2007 e Projeto de Pesquisa Capital Social e Desenvolvimento Territorial do Corede Nordeste. 


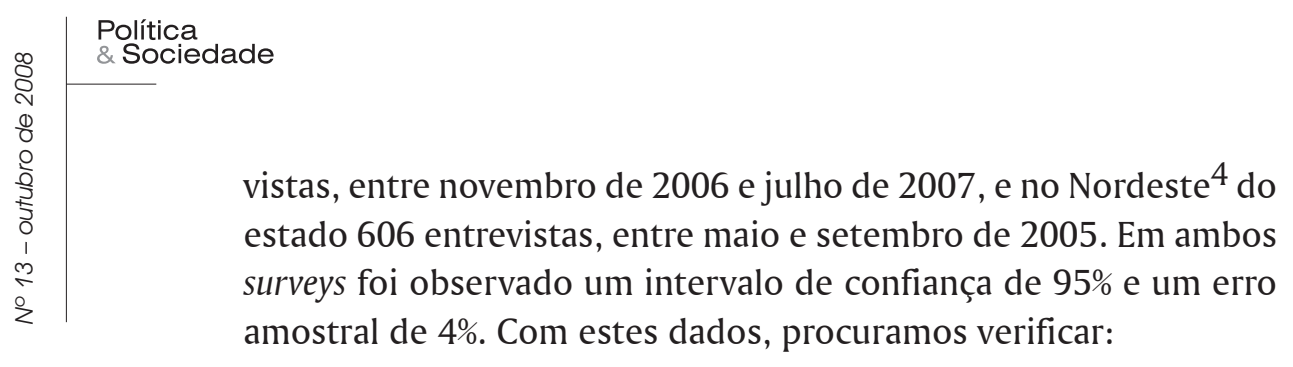

- Em que medida a confiança interpessoal pode estar associada à crença na democracia?

- Em que medida as duas regiões, em perspectiva comparada, apresentam uma regularidade para além das idiossincrasias destas regiões?

- Quais são as particularidades de cada uma?

- Como capital social e democracia estão associados em cada caso?

A resposta nessas indagações tem como propósito fornecer subsídios para testarmos nosso quadro teórico e para compreendermos as condições que favorecem a democracia na região.

\section{As possibilidades da democracia}

Dentro da ótica institucionalista pode-se afirmar que o Brasil vive, neste início de século XXI, um regime do tipo democrático. De acordo com os escritos de Dahl (1971), isso significa que nosso sistema politico é congruente com as oito premissas estabelecidas pelo autor para que um sistema possa ser considerado democrático. Ou seja, há eleições regulares, abertas e competitivas; os líderes são escolhidos por meio de mecanismos eleitorais claros e governam por meio das instituições governamentais por tempo determinado; a sociedade tem o direito à organização e a contestação política é permitida. Em outras palavras a poliarquia está instituída. Este regime foi resultado de uma construção histórica e política recente, pois desde o golpe militar de 64, até meados da década de 80 ,

4 Dados referentes à Pesquisa: Capital Social e Desenvolvimento Regional:A importância do capital social no desenvolvimento territorial do Corede Nordeste que contou com o apoio da FAPERGS, e foi realizado pela Universidade Estadual do Rio Grande do Sul - Unidade de Sananduva em parceria com a FEPAGRO. 
vivia-se sob um regime autoritário, numa sociedade reprimida e censurada fortemente pelo Estado.

O que interessa para os objetivos desta análise é o fato de que nos encontramos, hoje, numa situação política e institucional (legal) diferente destes anos pretéritos. De fato, o Brasil sofreu mudanças significativas nas últimas décadas, transitou de seu regime "não-democrático" para uma forma "democrática de governo". Uma verdadeira "onda democrática”, para usar a expressão de Huntignton (1994), atingiu diferentes países no continente americano, afetando inclusive o Brasil. Nesta perspectiva, o autor identifica ondas de democratização que sucedem-se, uma após outra, intercaladas por ondas reversas. A terceira onda democratizadora teve seu início com a revolução dos Cravos (abril de 1974, em Portugal), logo espalhando-se pelo continente europeu e latino-americano, levando importantes países a elegerem governos civis-democráticos. Todavia, este fenômeno trouxe uma tarefa bastante complexa para a comunidade acadêmica, à medida em que tornou-se necessário explicá-lo.

Assim, é preciso dizer que não há uma unanimidade entre os cientistas políticos para explicar o fenômeno da democracia. Aliás, existe muito desacordo nesta matéria, o que nos leva a diferentes enfoques a respeito da questão em debate. Há autores, por exemplo, que explicam a democracia pelas estruturas, isto é, os teóricos da modernização, que colocam a democracia como resultado direto do desenvolvimento econômico; enquanto outros apostam na qualidade dos atores (das lideranças políticas) que, a partir de suas escolhas racionais, tornam a democracia possível.

\subsection{Os teóricos da modernização}

As teorias da modernização, afloradas após a Segunda Guerra Mundial, entendiam que a modernização levaria, inevitavelmente, à democracia, isto é: o crescimento econômico, a urbanização, os índices crescentes de melhora no nível educacional das populações, bem como de saúde, somados a uma visão de futuro e confiança tenderiam a edificar sociedades democráticas, pois tais sociedades demandariam pessoas, indivíduos autônomos 
e organizados. Apostava-se, em última análise, que as estruturas condicionariam os processos de mudança política. Esta modernização aparecia como condição necessária para a emergência e estabilidade de um governo democrático (NUN, 1994). Era uma visão evolucionista da sociedade que contrapunha o tradicional ao moderno. Desta forma, a modernização levaria à democracia. Daí, todos os esforços das lideranças políticas em criar as condições objetivas para a democracia, dando-se ênfase forte nos aspectos econômicos em detrimento dos políticos.

O péssimo desempenho da economia brasileira na década de 80 (a chamada década perdida), não provocou um recuo da democracia recém instalada, colocando por terra a variável "econômica”, pois, se as condições econômicas (o crescimento da economia) fossem indispensáveis e determinantes para a democracia, o Brasil teria retornado ao regime autoritário (MAINWARING, 1992). Portanto, a dimensão econômica enfatizada na teoria da modernização mostrava-se impotente para explicar não só as possibilidades da democracia, como os processos de transição democrática, na medida em que perdera seu poder de explicação. Se a modernização por meio da urbanização, maior acesso à educação e crescimento econômico não explicam a democracia, o que poderá explica-lá melhor?

\subsection{A aposta nos atores políticos}

A explicação que vai contrapor-se à da modernização é a dos atores políticos na tradição de autores como O'Donnell e Schmitter, (1986; 1988). Se a teoria da modernização, como vimos, falhava por enfatizar os aspectos estruturais (econômicos e sociais) em prejuízo dos aspectos políticos, esta nova vertente teórica irá, contrariamente, enfatizar os atores (as lideranças políticas) e suas ações racionais, em prejuízo à dimensão estrutural (modernização). Ou seja, mesmo levando em conta as condições econômicas da transição à democracia que estavam na base do processo histórico brasileiro, esta vertente considerou que o resultado final dos processos de mudança (a passagem do autoritarismo para a democracia) dependeria, basicamente, da capacidade das lideranças políticas mais expressivas 
do país aproveitarem ao máximo as oportunidades que surgiram no contexto político da época para tomarem suas decisões e levarem o Brasil à democracia (MOISÉS, 1995).

Estas posições de fato inovam teoricamente o debate à medida em que elas quebram com o determinismo, que era próprio das avaliações da teoria da modernização, colocando a democracia de uma maneira linear, apresentando-a num suceder de fatos e acontecimentos previsíveis. Ao contrário, os acontecimentos são inesperados e muitas vezes imprevisíveis politicamente, pois tanto do lado daqueles que estão na condução do regime, como daqueles que estão na oposição, há uma intensa negociação, em que as lideranças políticas envolvidas escolhem o melhor caminho para construir a democracia. No Brasil, escolhemos o caminho institucional, isto é, escolheu-se chegar à democracia seguindo o calendário eleitoral, parlamentar, gradativamente, o chamado "cálculo da descompressão" (LAMONIER, 1987). Esta precisão analítica tornou-se fundamental para compreendermos que os processos de mudança política no Brasil não deram-se de forma bipolar entre o regime e a oposição, mas que envolveram uma complexa trama de relações em que tanto as lideranças do regime autoritário, quanto as lideranças da oposição a ele, tiveram um papel importante na articulação das possibilidades da democracia.

Isto não significou, entretanto, que essa vertente negasse fatores estruturais, macroeconômicos, relativos à sistemática mundial ou mesmo nacional, todavia o alto grau de incerteza presente nestes processos faz com que a qualidade da liderança e suas capacidades sejam decisivas, ou seja, a escolha dos atores diante dos acontecimentos é que tornará a democracia possível, que, em última análise, depende de fatores domésticos, da decisão das lideranças envolvidas no processo político em implantá-la.

Posto desta forma, fica evidente que estas duas vertentes explicam de maneira diferente o fato da democracia ter-se tornado possível no Brasil. Todavia, esta segunda vertente falhou na capacidade de prognosticar o futuro do país; digamos que alguns acontecimentos que a teoria previu no processo político brasileiro de construção democrática não ocorreram. 


\subsection{As Promessas não cumpridas}

Para estes estudiosos da democracia, a passagem de um "regime político a outro" pode ser categorizado como uma transição, um complexo processo no qual desdobrariam-se passos sequienciais do regime autoritário à democracia. Resumidamente, essa vertente explicativa apresenta cinco suposições, segundo Carothers (2002). A primeira suposição é de que um país como o Brasil, que estava saindo de um regime autoritário (um país que "pegou" a onda da democracia) poderia ser considerado uma nação em mudança: em transição à democracia. A segunda é que esta tendência desdobrarse-ia em sequiências e estágios, primeiramente ocorrendo a abertura, depois o colapso do regime e, posteriormente, a consolidação, em que a democracia formal (leis e regras) seria transformada em democracia substantiva (ganhos sociais econômicos). A terceira suposição é de que as eleições serviriam para alargar a participação política e a responsabilidade democrática do Estado em relação a população. A quarta suposição pressupõe que a transição seria uma decisão das elites políticas, como já colocamos e, finalmente, a quinta suposição, que colocaria os processos de democratização como redesenhando as instituições do Estado.

De fato, a experiência histórica tratou de quebrar estas suposições, para o referido autor, porquê:

1ํ) Os países que estavam em "transição" praticamente não democratizaram-se;

$2^{\circ}$ ) Os estágios presumidos não foram obedecidos como no esquema teórico;

$3^{\circ}$ ) A regularidade das eleições não levaram à responsabilidade política dos governantes.

4ํ) A democratização não é uma tarefa determinantemente dependente das elites políticas, mas também de fatores estruturais;

5) A construção do Estado tem sido um assunto muito mais complexo do que supunham inicialmente os teóricos.

Nesta direção, e valendo-se da advertência de que a construção da democracia não é uma tarefa apenas das elites políticas, 
mas também depende de fatores estruturais, há uma retomada da teoria da modernização, porém sob um novo aspecto.

\subsection{A retomada das análises estruturais}

No que diz respeito à dimensão estrutural da transição (os aspectos relacionados à modernização), o Professor Huntington (1994), em seu livro "A Terceira Onda", retomou as análises que enfatizavam a dimensão econômica, porém de uma maneira diferente. Ele procurou dar uma "explicação" aos processos de democratização que começaram na década de setenta, levando cerca de 30 países "não-democráticos" a "regimes democráticos". A centralidade de sua análise reside na busca de uma correlação entre riqueza e democratização, mas não ao modelo das "velhas análises", que afirmavam ser os países ricos democráticos e que a riqueza geraria instantaneamente a democracia.

Embora saliente que os fatores econômicos não sejam determinantes para promover a democratização, eles produzem um impacto significativo. Neste sentido, sua argumentação vai demonstrar uma correlação positiva entre riqueza e democratização, porém enfatizando que não somente a riqueza, mas a sua permanência, a longo prazo, podem promover um ambiente propício à democratização. Assim, no Brasil, o próprio desenvolvimento econômico patrocinado pelo regime autoritário nos anos 1970 teria, ironicamente, criado as condições para a sua própria superação nos anos 1980, pois modernizou o país.

A verdade é que o desenvolvimento econômico cria um lastro favorável para a democratização à longo prazo, porém as crises de curto prazo ou os surtos econômicos da conjuntura podem apresentar-se como inflexões poderosas que abalam mais o autoritarismo do que a democracia, isto porque a "legitimidade do governo" nas democracias é separada da "legitimidade do regime". Isso quer dizer que, nas democracias, se os governos perdem legitimidade, se o presidente perde prestígio perante a população, o regime (regras de funcionamento da democracia) ganha, pois possibilita a alternância do poder. No caso dos regimes autoritários, o "regime" e o "governo" formam uma coisa só, pois não há alternância no poder ou ela é baixa. 


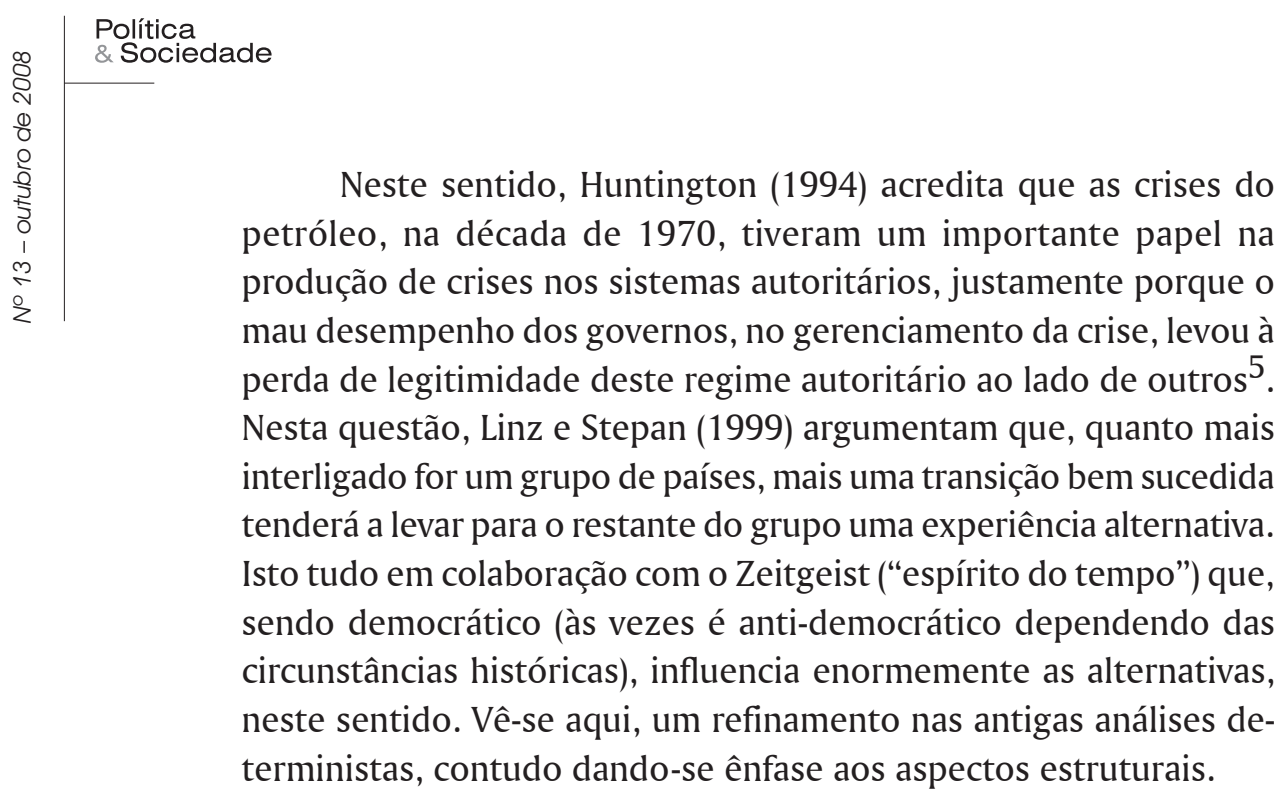

\section{Um modelo alternativo para compreender-se a democracia: o capital social}

Weber já havia sublinhado que nas Ciências Sociais incorremos no risco do erro ao apostarmos na monocausalidade para a explicação de um problema sociológico, pois existem diferentes fatores que podem estar contribuindo para a ocorrência de determinado fenômeno. Desta forma, seguindo os estudos contemporâneos sobre a democracia, podemos flexibilizar tanto as "apostas estruturais" como as apostas nos "atores" que estamos discutindo. Ou, como propõe José Álvaro Moisés (1995), um modelo balanceado, mais abrangente, que supere as visões unilaterais (estrutura e atores) do que ele chama de "maximalismo" e "minimalismo".

Grosso modo, podemos dizer que a perspectiva "minimalista" parte do pressuposto de que a democracia é possível sob condições mínimas, ou seja, não é preciso pré-requisitos econômicos, sociais

5 Ao lado deste seu forte argumento, ele também salienta três outros aspectos que ajudariam a explicar a terceira onda: a mudança na doutrina da Igreja católica, que a partir do Concílio de Vaticano II, entre 63 e 65, passaram a apoiar a democracia; o incentivo americano a partir de 74 , com sua política dos direitos humanos e, finalmente, o fenômeno dos efeitos demonstração que forneceram e exportam modelos de democratização por meio do desenvolvimento dos meios de comunicação. 
ou mesmo culturais para que ela estabeleça-se, pois ela dependeria basicamente da escolha dos atores envolvidos, dos seus pactos, de certas regras. É a aposta nos atores políticos, como vimos. Porém, estes pactos não são efetuados, porque os atores não têm a democracia como um valor em si, mas escolhem-na instrumentalmente, pois é a melhor forma de sobreviverem politicamente. Já na perspectiva "maximalista", parte-se do pressuposto que a democracia não é possível sob condições mínimas; que condições econômicas, sociais e culturais exercem um importante condicionamento sobre ela. Não haveria sustentação da democracia sem esses lastros, sem um apoio normativo a ela.

Nesta sua concepção, deve-se levar em conta tanto a liberdade de escolha dos atores políticos no curso das transformações proporcionadas pelos processos de mudança política, como os condicionantes impostos a estas situações dado pela presença ou ausência de condições sociais, econômicas, políticas e culturais. Então, enquanto as mudanças econômicas e sociais induzidas pelos processos de modernização econômica ampliam as bases, a partir das quais essas iniciativas podem ser tomadas, cabe ao esforço das lideranças políticas gerar as condições de sucesso da criação da democracia (MOISÉS, 1995).

Atores que fazem suas escolhas sob condições favoráveis à democracia têm grande possibilidade de lograr êxito, porém Moisés (1995) vai além; ela só efetivará, dotando-se os governos de mecanismos que lhes dêem autoridade para gerar e implementar políticas e, principalmente, criar instituições que sejam respaldadas por atitudes e comportamentos democráticos das massas. É desta forma que seu "modelo balanceado" (entre os maximalistas e minimalistas) faz chamar a atenção para a dimensão da cultura política como um fator indispensável para a construção de regimes democráticos. A variável "cultura política” é introduzida no debate, entendida aqui como um conjunto de atitudes e comportamentos que os cidadãos tem em relação ao sistema político e que são indispensáveis para a sustentação das instituições da democracia. (ALMOND \& VERBA, 1989).

De fato, não se pode afirmar que parcelas significativas de cidadãos que rejeitam ou são indiferentes aos valores democráticos 
(que não possuem uma cultura de afirmação dos valores democráticos, por exemplo) não possuam uma variável comprometedora da estabilidade política. Na verdade, estas parcelas de eleitores podem ter papel decisivo na manutenção de um sistema intolerante e instável, não permitindo a construção de regimes democráticos no país. Assim, ao contrário das democracias ocidentais, onde já existe um regime democrático construído, o elemento da cultura política talvez não seja tão importante, mas no Brasil sim, para o eficiente funcionamento da democracia, conclui Baquero (1999).

Não trata-se aqui de negar que no Brasil, nos últimos anos, tivemos um avanço significativo em relação à democracia, e que mesmo não havendo um apoio normativo ao regime democrático no país, as eleições ocorrem regularmente, as instituições de certa forma funcionam e nada aponta para um retrocesso ao autoritarismo. E nao se pode negar que houve, de uma maneira geral, uma modernização das instituições no país, assim como das suas leis, apesar da ainda existente precariedade da funcionalidade da lei, das regras e da democracia.

O antropólogo Roberto da Matta (2001), a respeito das discrepâncias entre o Brasil legal e o Brasil real, ou, como diriam os cientistas políticos, do distanciamento entre o Estado e a sociedade, alude para o fato de que o "jeitinho brasileiro" é, na verdade, uma forma de navegação social, em que as pessoas apelam para um "pistolão", "um conhecido", "um jeito diferente" para resolver seus problemas, porque não há uma correspondência entre o que é legal e o comportamento social. Nesse ponto entra em cena o "jeitinho brasileiro", em que as pessoas não são tratadas como cidadãs, mas de acordo com o pertencimento - ou não - à determinada classe social. Então, para além da dimensão legal, institucional, é preciso uma certa mudança na cultura política da sociedade para viabilizarmos o melhor funcionamento da democracia destas leis. Baquero (2005) usa o conceito de democracia inercial para referir-se à democracia brasileira. Para o autor, há uma modernização das instituições políticas, uma evolução das leis, das regras, no sentido poliárquico, entretanto, pouco ou nada evoluem na dimensão social, ou seja, é uma democracia inercial, que apresenta as seguintes características: a) políticas econômicas que não favorecem as massas excluídas e que 
mantêm o desemprego inalterado e estagnado; b) uma cultura híbrida (misturada) que institucionaliza, um comportamento de resignação e hostilidade com a política. Esta cultura política de resignação e hostilidade traduz-se em uma cultura de desconfiança generalizada em relação a política, mas também nas relações interpessoais na base da sociedade. $O$ problema deste tipo de configuração cultural é que ele impede o funcionamento da democracia.

Existe na literatura contemporânea das Ciências Socais uma renovação dos estudos sobre cultura política em que têm-se buscado as razões (o elemento-chave) para o funcionamento adequado ou não da democracia ${ }^{6}$. O elemento-chave para o funcionamento da democracia seria o capital social, conceito este que vem sendo bastante difundindo e discutido nos meios acadêmicos neste início de século. De acordo com estas novas discussões, quanto mais "capital social" tem uma sociedade, mais possibilidade existe da democracia florescer. Ao contrário, quanto menos "capital social" existe numa determinada sociedade, menores são as chances deste regime político.

Vários autores das Ciências Sociais vêm contribuindo para esta formulação conceitual, como Pierre Bourdieu, Colleman, Francis Fukuyama e Putnam. Contudo, para este artigo será usado o conceito desenvolvido por Robert Putnam (2000) para definição do conceito de "capital social". Segundo este pesquisador, o conceito diz respeito às práticas sociais, normas e relações de confiança que existem entre cidadãos numa determinada sociedade, bem como sistemas de participação e associação que estimulam a cooperação. Então, quanto maior for a capacidade dos cidadãos de confiarem uns nos outros, para além de seus familiares, assim como maior e mais rica for o número de possibilidades associativas numa sociedade, maior será o volume de "capital social". A questão central para Putnam (2000) é que confiança, cooperação, espaços de participação social entre o Estado e a sociedade são elementos positivos e essenciais para o bom funcionamento das democracias.

6 O funcionamento adequado da democracia, aqui, não é só a capacidade que o regime democrático tem para resolver conflitos políticos, acomodar os interesses das elites, processar o dissenso, porém sua capacidade em ser eficiente e sensível as demandas da população (Putnam, 2000). Em outras palavras, em resolver os problemas da saúde, da educação, da segurança, do emprego, do campo etc. 
Desta forma, buscando operacionalizar a hipótese deste autor, passaremos a analisar a relação entre capital social e as instituições da democracia nas duas regiões do Rio Grande do Sul: Vale do Rio dos Sinos e Nordeste, enfatizando preferencialmente a dimensão da confiança interpessoal e a crença nas instituições democráticas.

\section{Democracia e capital social}

As tabelas a seguir têm a finalidade de apresentar os indicadores de capital social coletados pelas duas pesquisas citadas. Para podermos desenvolver nossa hipótese as tabelas serão apresentas com o intuito de caracterizar as duas regiões nos seus indicadores de capital social.

Iniciamos o desenvolvimento do trabalho levantando os dados sobre a confiança interpessoal, que constitui um dos elementos-chaves do "capital social" e que se coloca como um fator importante para a sustentação da democracia. Neste quesito, numa perspectiva comparada, nos três gráficos iniciais têm-se o propósito de medir a confiança interpessoal. Como pode ser observado no Gráfico 1, quando questionada à respeito de confiança interpessoal, em termos gerais, a população do Corede do Vale do Rio dos Sinos apresenta o maior percentual de confiança com 30,8\% em relação a região Nordeste com 19,2\%.

\section{Gráfico 1 - Confiança Interpessoal}

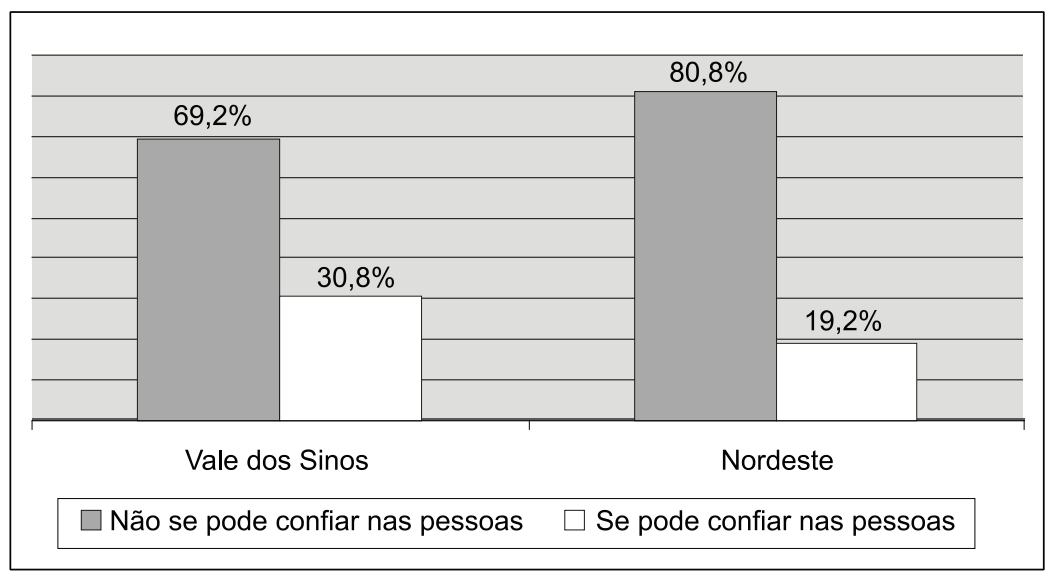

Fonte: Grupo de Pesquisa em Desenvolvimento Regional CPP/Feevale e Projeto de Pesquisa Capital Social e Desenvolvimento Territorial do Corede Nordeste. Total: Vale dos Sinos $\mathrm{N}=600$ - Nordeste $\mathrm{N}=606$. 
Porém, quando observamos os dados mais específicos em relação à questão da confiança interpessoal, como a confiança nos vizinhos, o índice da região Nordeste é superior $(76,0 \%)$ a região do Vale dos Sinos $(71,3 \%)$, conforme Gráfico 2.

Gráfico 2 - Confiança nos vizinhos

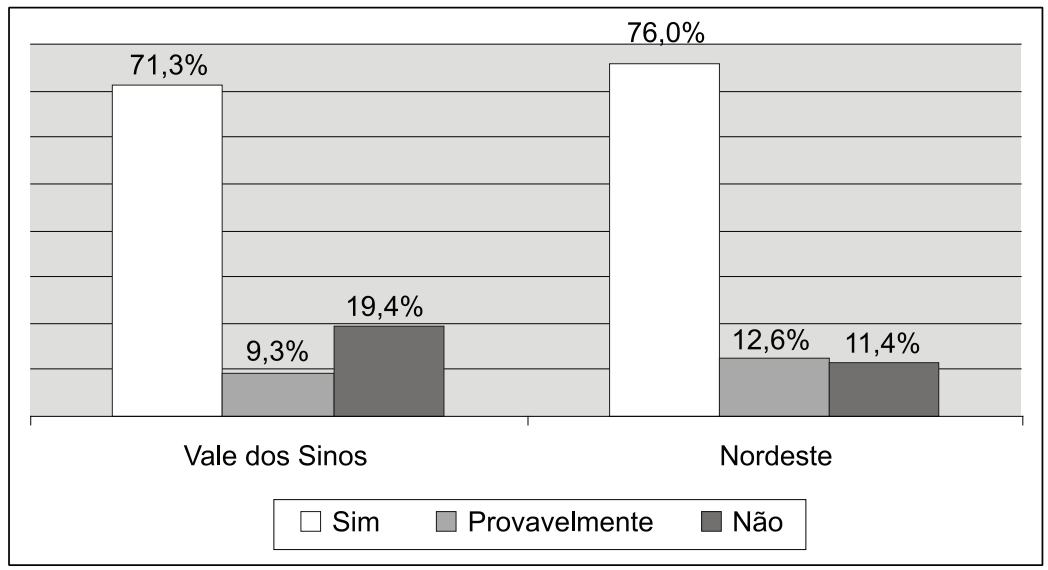

Fonte: Grupo de Pesquisa em Desenvolvimento Regional CPP/Feevale e Projeto de Pesquisa Capital Social e Desenvolvimento Territorial do COREDE Nordeste. Total: Vale dos Sinos $\mathrm{N}=600$ - Nordeste $\mathrm{N}=606$.

O Gráfico 3 diz respeito à confiança para as demais esferas sociais de interação, como colegas de trabalho e familiares, questionando a quem o entrevistado pediria ajuda em uma situação de emergência. Enquanto que 82,0\% dos respondentes do Vale dos Sinos afirmaram que pediriam auxilio aos familiares, este percentual desce para $64,0 \%$, na região Nordeste, sinalizando um aumento na confiança fora do círculo de familiares nesta região. Ou seja, no Corede Nordeste, como se pode observar no Gráfico 3, aumenta o percentual de confiança nos vizinhos e colegas de trabalho para $16 \%$, contra $10,5 \%$ no Corede do Vale do Rio dos Sinos. 


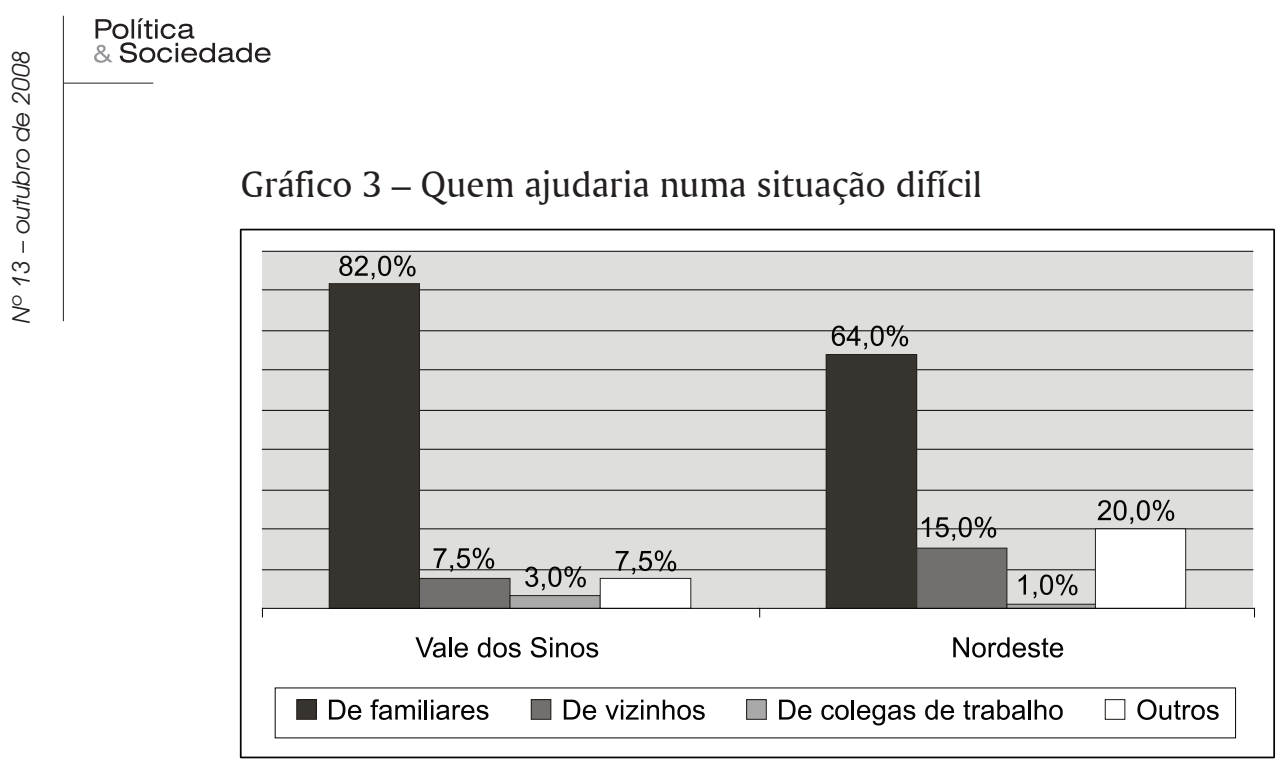

Fonte: Grupo de Pesquisa em Desenvolvimento Regional CPP/Feevale e Projeto de Pesquisa Capital Social e Desenvolvimento Territorial do Corede Nordeste. Total: Vale dos Sinos $\mathrm{N}=600$ - Nordeste $\mathrm{N}=606$.

Como nossa hipótese diz respeito à relação entre capital social e democracia, é importante apresentar os dados observados quanto à satisfação dos entrevistados nessas regiões sobre o funcionamento democrático. Nessa direção, no Gráfico 4 observa-se que os habitantes do Corede do Vale do Rio dos Sinos são os menos satisfeitos com o funcionamento da democracia $(44,0 \%)$, enquanto que na região Nordeste este percentual desce para $31,2 \%$ dos respondentes. De maneira esperada a satisfação com a democracia esta mais no Nordeste $(17,9 \%)$ do que no Vale do Rio dos Sinos $(9,9 \%)$. Quanto maiores são os percentuais de confiança, maiores são as possibilidades de satisfação com a democracia. 


\section{Gráfico 4 - Satisfação com a democracia}

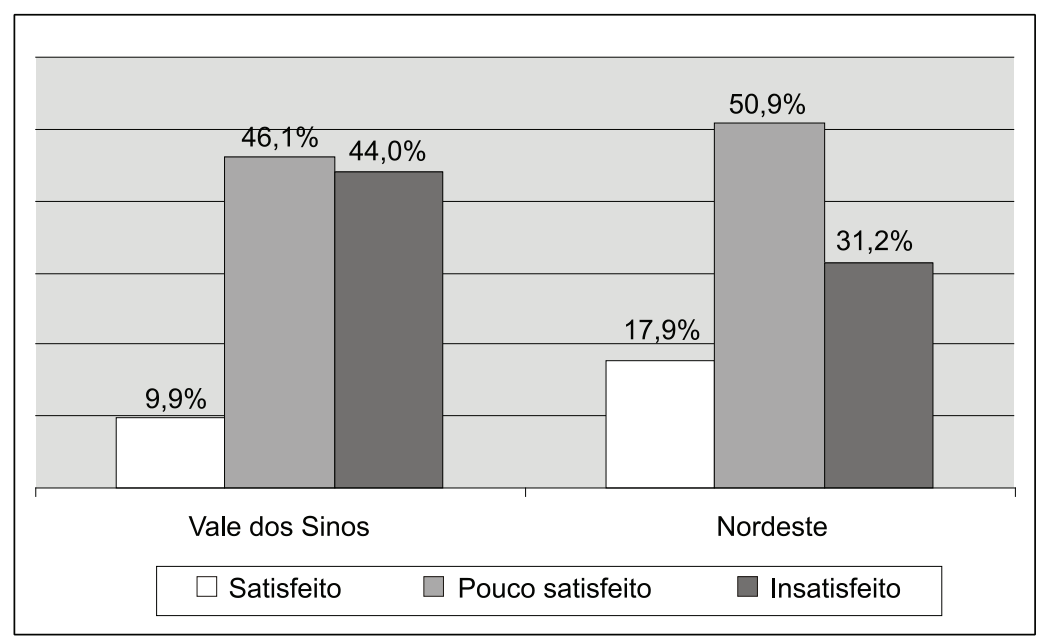

Fonte: Grupo de Pesquisa em Desenvolvimento Regional CPP/Feevale e Projeto de Pesquisa Capital Social e Desenvolvimento Territorial do Corede Nordeste. Total: Vale dos Sinos $\mathrm{N}=600$ - Nordeste $\mathrm{N}=606$.

\section{Observando a Tabela $1^{7}$, que se constitui em um Índice de}

7 Este Índice de Capital Social (ICS) foi construído de forma idêntica para os dois Corede a partir da seleção de 9 questões relativas ao capital social, são elas: "Em termos gerais, o senhor diria que se pode confiar nas pessoas ou não se pode confiar nas pessoas?" Sim (peso 2), Não (peso 0); “Gostaria de saber se o senhor confia muito (peso 2), pouco (peso 1) ou não confia (peso 0) na: igreja, família, vizinhos, associações comunitárias, sindicatos"; "O senhor costuma participar de: partidos políticos, reuniões políticos, comícios, associações comunitárias, associações religiosas, associações sindicais, conselhos populares, ONG's, orçamento participativo, abaixo assinados, manifestações ou protestos, greves, ocupação de terrenos ou prédios públicos, outros" Sim (peso 2), Não (peso 0); "Nos últimos anos, o senhor tentou resolver algum problema local do bairro/ comunidade junto com outras pessoas? Sim (peso 2), Não (peso 0); “Dentre os grupos que eu vou mencionar, quais deles existem no seu bairro: grupo político, grupo ou associação cultural, grupo educacional, grupo esportivo, grupo de jovens, ONG ou grupo cívico, grupo baseado na comunidade étnica, grupos de mulheres, outro" Sim (peso 2), Não (peso 0); "Atualmente o senhor participa de algum grupo ou organização?” Sim (peso 2), Não (peso 0); "Se precisasse viajar por um ou dois dias, o senhor poderia contar com vizinhos para cuidar da sua casa e/ou filhos?" Sim (peso 2), Provavelmente (peso 1), Não (peso 0); "Em uma situação de emergência como a doença de um familiar ou perda de emprego, o senhor receberia ajuda:" familiares (peso 0), vizinhos (peso 2), colegas de trabalho (peso 2); "Se um projeto da comunidade não lhe beneficia diretamente, 
Capital Social construído a partir de nove questões, vemos que os estoques de capital social são maiores no Corede Nordeste em comparação com o Corede Vale do Rio dos Sinos. Neste último, a média de capital social é de 0,292 e no Nordeste é de 0,426. Aplicando-se o teste $t$ no Corede Nordeste temos capital social médio significativamente maior do que no Corede Vale do Rio dos Sinos $(t=18,591 ; p=0,000)$.

Tabela 1 - Índice de Capital Social (ICS) Corede Nordeste e Vale dos Sinos

Corede Vale dos Sinos

Alto

Médio

Baixo

Total
5

203

392

600
$0,8 \%$

$33,8 \%$

$65,3 \%$

$100 \%$

Corede Nordeste 35 $5,8 \%$

434 $71,6 \%$

137 $22,6 \%$

Fonte: Projeto de Pesquisa Capital Social e Desenvolvimento Regional: a importância do capital social no desenvolvimento territorial do Corede Nordeste e Grupo de Pesquisa em Desenvolvimento Regional/CPP FEEVALE. Total: 1206

Seguindo a questão democrática, é importante apresentar os dados referentes à confiança institucional que a população dessas regiões nutre por suas instituições. Sendo assim, é importante estabelecer uma relação de associação entre confiança institucional e democracia.

O Gráfico 5 descreve a relação de confiança da população local com o Congresso Nacional. No Corede do Vale do Rio dos Sinos, $54,3 \%$ dos entrevistados responderam que não confiam nesta instituição, já no Nordeste este percentual cai para 49,3\%, aumentando o percentual de quem confia muito para $2,7 \%$.

mas pode beneficiar outras pessoas do seu bairro, o senhor contribui pra este projeto?" Sim (peso 2), Não (peso 0). 


\section{Gráfico 5 - Confiança no Congresso Nacional}

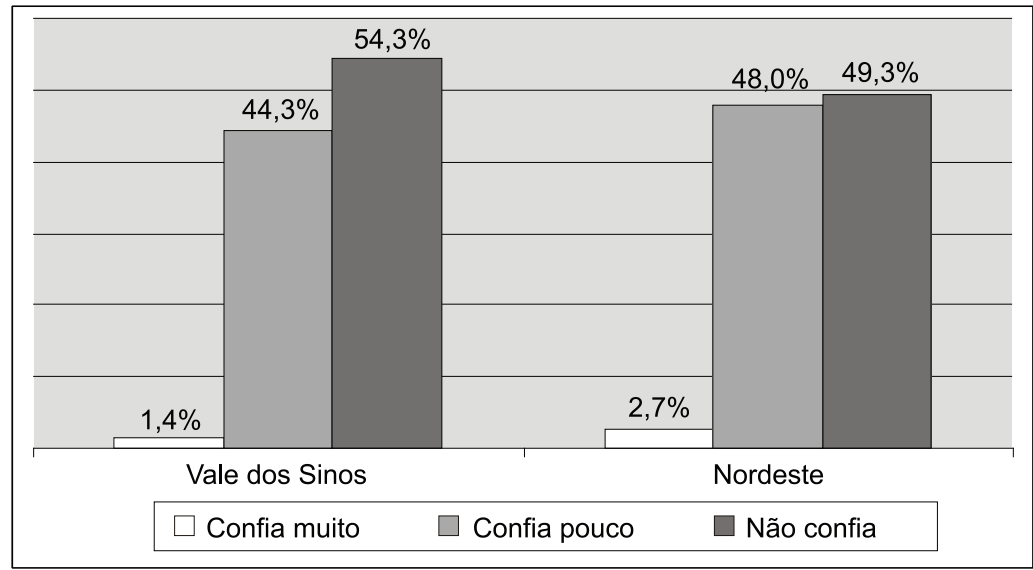

Fonte: Grupo de Pesquisa em Desenvolvimento Regional CPP/Feevale e Projeto de Pesquisa Capital Social e Desenvolvimento Territorial do Corede Nordeste. Total: Vale dos Sinos $\mathrm{N}=600$ - Nordeste $\mathrm{N}=606$.

Em relação ao nível de confiança depositada no Governo Federal, observa-se no Gráfico 6 que na região do Vale dos Sinos 44,4\% não confiam no Governo Federal, na região Nordeste este percentual cai para 37,2. O percentual de quem confia muito varia negativamente em 7,0\%, entretanto há uma tendência geral no Nordeste de confiar mais nesta instituição do que no Vale do Rio dos Sinos.

Gráfico 6 - Confiança no Governo Federal

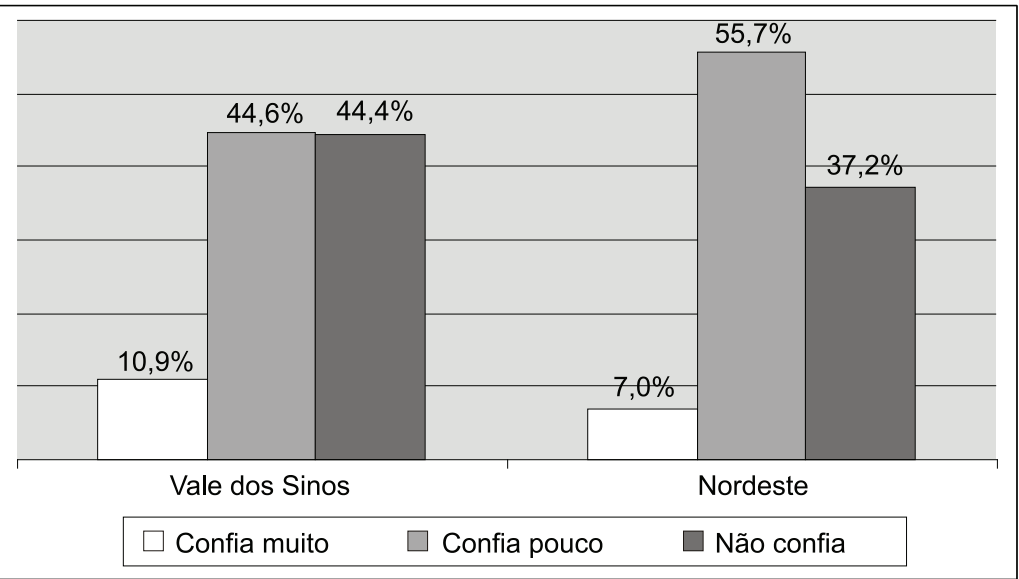

Fonte: Grupo de Pesquisa em Desenvolvimento Regional CPP/Feevale e Projeto de Pesquisa Capital Social e Desenvolvimento Territorial do Corede Nordeste. Total: Vale dos Sinos $\mathrm{N}=600$ - Nordeste $\mathrm{N}=606$. 
No quesito sobre a resolução dos problemas no Brasil, a análise do Gráfico 7 mostra que no Vale do Rio dos Sinos 69,3\% das pessoas responderam que a participação da população seria a melhor alternativa para resolver os problemas do país, enquanto que no Nordeste $58,7 \%$ deram a mesma reposta. Aqui se observa um paradoxo quando comparamos com os resultados que veremos na sequiência, no Gráfico 8, de participação em grupos societais. Se a população do Vale dos Sinos aposta na sua participação para mudar as coisas, como explicar então um índice tão baixo de envolvimento em ações da comunidade? Uma das explicações plausíveis seria o fato de que a participação no sistema democrático é reconhecida como apoio difuso, existente em muitas sociedades, mas não como apoio específico (EASTON, 1968). Some-se também a este fenômeno, como lembra Putnam (1996), o fato de que as zonas mais urbanizadas tendem a desfavorecer o acúmulo de capital social e, consequientemente, há um declínio da participação social.

Gráfico 7 - Resolução dos problemas do Brasil

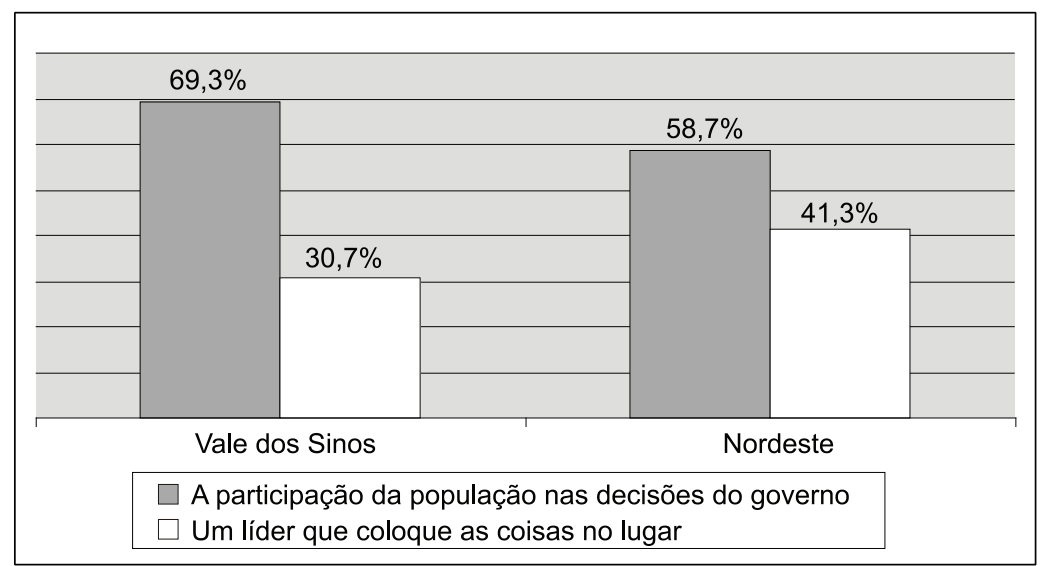

Fonte: Grupo de Pesquisa em Desenvolvimento Regional CPP/Feevale e Projeto de Pesquisa Capital Social e Desenvolvimento Territorial do Corede Nordeste. Total: Vale dos Sinos $\mathrm{N}=600$ - Nordeste $\mathrm{N}=606$.

A aposta na participação popular fica com os maiores escores nas duas regiões, muito embora a região do Vale dos Sinos apresente baixíssimo índice de participação em organizações ou grupos da sociedade, de uma maneira geral, em relação ao percentual da par- 
ticipação popular, como podemos observar no Gráfico 8. O Corede Vale dos Sinos fica com o menor percentual $(18,4 \%)$ e o Nordeste com 56,3\%. A região mais urbanizada participa menos, enquanto na região rural observa-se um índice bem maior de participação em grupos ou organizações dentro da comunidade. Como argumenta Pase (2006) em sua investigação, os estoques de capital social nos espaços rurais são superiores ao que ocorre no espaço urbano. Pelo menos neste caso comparativo, a tese do autor confirmou-se.

Gráfico 8 - Atualmente o/a sr/a participa de algum grupo ou organização

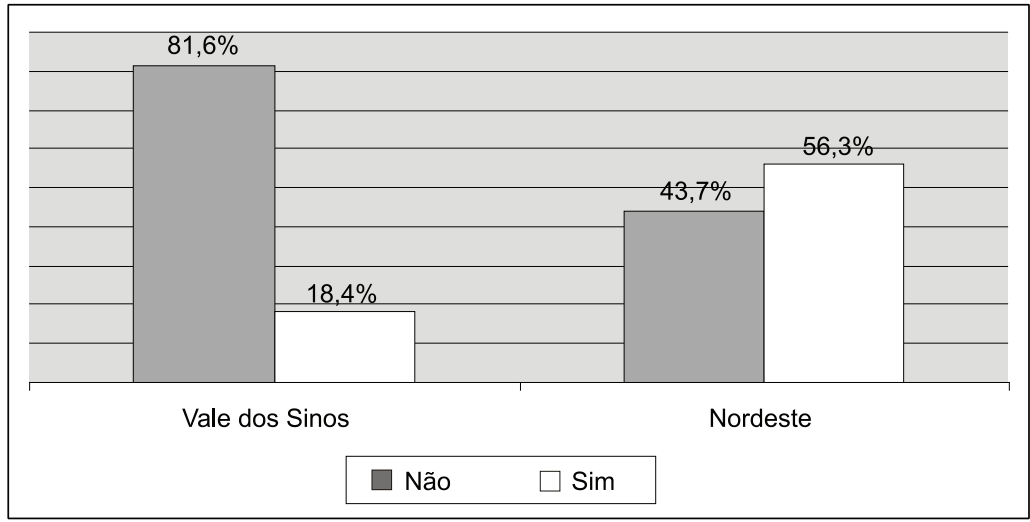

Fonte: Grupo de Pesquisa em Desenvolvimento Regional CPP/Feevale e Projeto de Pesquisa Capital Social e Desenvolvimento Territorial do Corede Nordeste. Total: Vale dos Sinos $\mathrm{N}=600$ - Nordeste $\mathrm{N}=606$.

Estes dados podem ser mais bem compreendidos quando cruzamos "confiança nas pessoas" e "satisfação com a democracia" nas duas regiões investigadas. Na perspectiva apontada pelos dados já analisados, observamos no Gráfico 9, de maneira geral, que a confiança interpessoal e satisfação com a democracia combinamse nos escores $13,9 \%$ no Vale dos Sinos e $27,4 \%$ no Nordeste. Estes escores alteram-se quando a confiança cai. Então temos uma diminuição da satisfação com a democracia, ficando em $8,4 \%$ no Vale dos Sinos e 15,6\% no Nordeste. Ou seja, quando a confiança interpessoal nestas populações diminui, igualmente a satisfação com a democracia também diminui. 
Gráfico 9 - Confiança Interpessoal e satisfação com a democracia

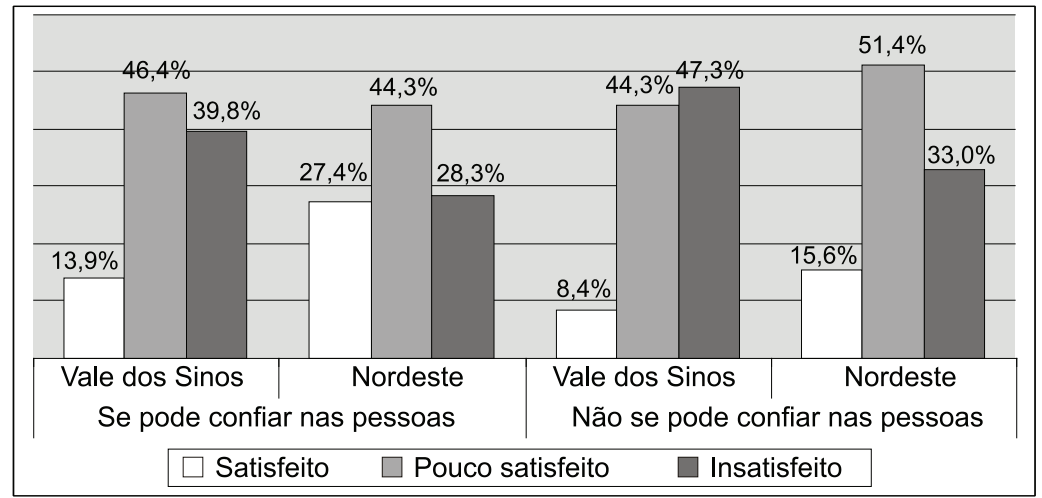

Fonte: Grupo de Pesquisa em Desenvolvimento Regional CPP/Feevale e Projeto de Pesquisa Capital Social e Desenvolvimento Territorial do Corede Nordeste. Total: Vale dos Sinos $\mathrm{N}=600$ - Nordeste $\mathrm{N}=606$.

Na sequiência de nossa análise, nos cruzamentos de confiança interpessoal com confiança nas instituições da democracia, como o Congresso Nacional, por exemplo, observamos no Gráfico 10 que a confiança nas pessoas está ligada à confiança no Congresso. Ou seja, quando diminui a confiança interpessoal nestas populações, diminui igualmente a confiança no funcionamento do Congresso. Tanto a população do Vale dos Sinos quanto a do Nordeste apresentaram uma tendência a confiar menos nesta instituição à medida que a confiança nas pessoas também cai.

Gráfico 10 - Confiança Interpessoal e confiança no Congresso Nacional

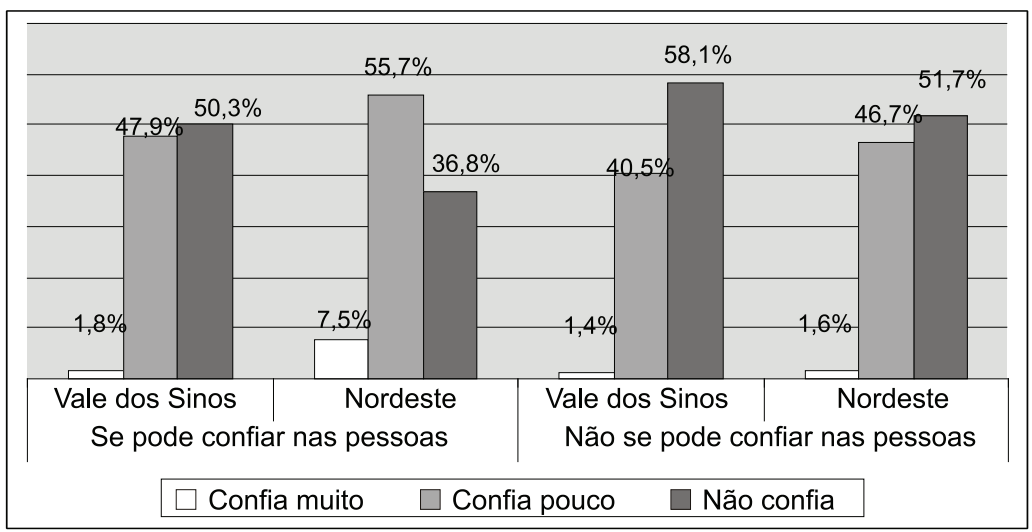

Fonte: Grupo de Pesquisa em Desenvolvimento Regional CPP/Feevale e Projeto de Pesquisa Capital Social e Desenvolvimento Territorial do Corede Nordeste. Total: Vale dos Sinos $\mathrm{N}=600$ - Nordeste $\mathrm{N}=606$. 
No Gráfico 11, corroborando com nosso argumento central, novamente a confiança interpessoal interliga-se com as instituições da democracia. Aqui, confiança interpessoal e confiança no Governo Federal estão relacionadas. Ou seja, quando diminui a confiança interpessoal nestas populações, diminui igualmente a confiança no governo federal, como também aconteceu em relação ao Congresso Nacional. As duas regiões analisadas apresentaram uma tendência a confiar menos na instituição Governo Federal na medida em que a confiança nas pessoas cai. Do total dos entrevistados no Vale dos Sinos que afirmaram confiar nas pessoas, 14,5\% afirmaram também confiar muito no Governo Federal, este percentual cai para $10,2 \%$ quando a confiança interpessoal decresce. No caso do Nordeste novamente, do total que afirmaram confiar nas pessoas, 16,2\% também afirmaram confiar muito no governo. Este percentual cai para 5,4\% quando a confiança interpessoal diminui.

Gráfico 11 - Confiança Interpessoal e confiança no Governo Federal

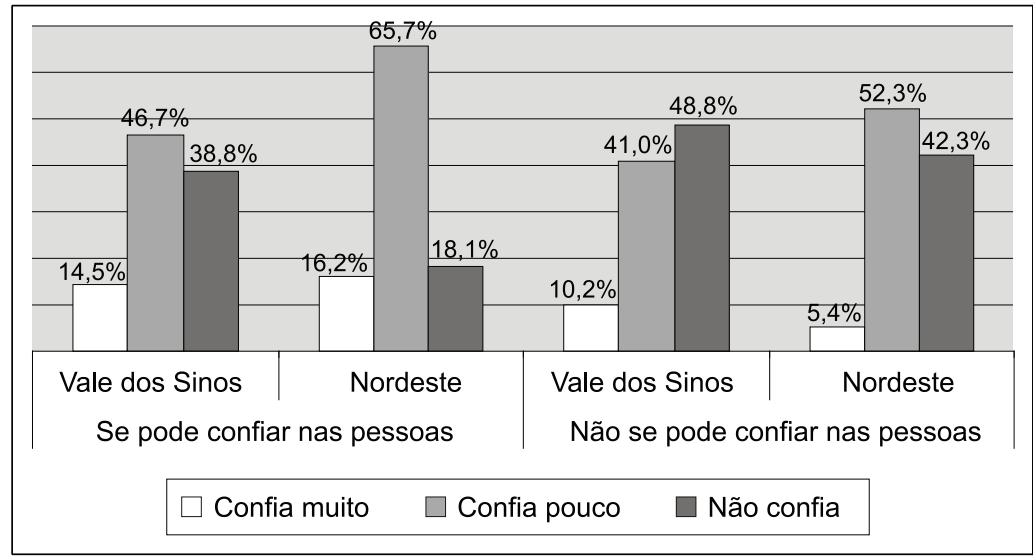

Fonte: Grupo de Pesquisa em Desenvolvimento Regional CPP/Feevale e Projeto de Pesquisa Capital Social e Desenvolvimento Territorial do Corede Nordeste. Total: Vale dos Sinos $\mathrm{N}=600$ - Nordeste $\mathrm{N}=606$.

Todavia, para corroborarmos nossa hipótese entre Capital Social e democracia aplicamos a análise de regressão colocando a "satisfação com a democracia" como variável dependente e 
as variáveis de "confiança" no Congresso Nacional, Governo Federal, Assembléia, Governo Estadual, Câmara Municipal, Governo Municipal, Judiciário, partidos políticos, polícia, igreja, família, vizinhos, associações comunitárias, sindicatos e meios de comunicação como variável independente. O teste demonstrou, no caso do Corede Nordeste, que existe uma associação significativa entre a variável "satisfação com a democracia" e a variável "Associação Comunitária" 0,004, e marginalmente significativa com Governo Federal" 0,007 e "Juízes" 0,008 (R 0,291 - F 3,615). No caso do Vale do Rio dos Sinos, aparece associada de maneira significativa com o Governo Federal 0,017, Polícia 0,024, partidos políticos 0,028 e marginalmente significativa para a Assembléia 0,051. (R 0,274 - F 2,269). Para nosso trabalho, o caso do Corede Nordeste confirma mais nossa hipótese do que o Corede Vale do Sinos neste teste específico, pois a confiança em "Associações Comunitárias" 0,004 explica melhor a relação com variável dependente "democracia"8.

Se a confiança interpessoal aparece relacionada com as instituições da democracia, como o Congresso e o Governo, ela também aparece fortemente ligada à participação popular em detrimento da confiança em líderes, a estilo das "democracias delegativas" (O’DONNELL, 1986). Se observarmos o Gráfico 12, veremos que, do total dos entrevistados no Corede do Vale do Rio dos Sinos que disseram ter confiança interpessoal, 28,8\% concordaram com a afirmação de que "um líder seria necessário para resolver os problemas do país" e 71,3\% concordaram que "o melhor seria a participação popular".

8 Não utilizamos a variável "confiança interpessoal" no teste de regressão, pois a forma padrão em que foi formulada a questão de maneira binária não permitiu a aplicação do teste em confronto com a variável "satisfação com a democracia". 
Gráfico 12 - Confiança Interpessoal e Resolução dos problemas do Brasil

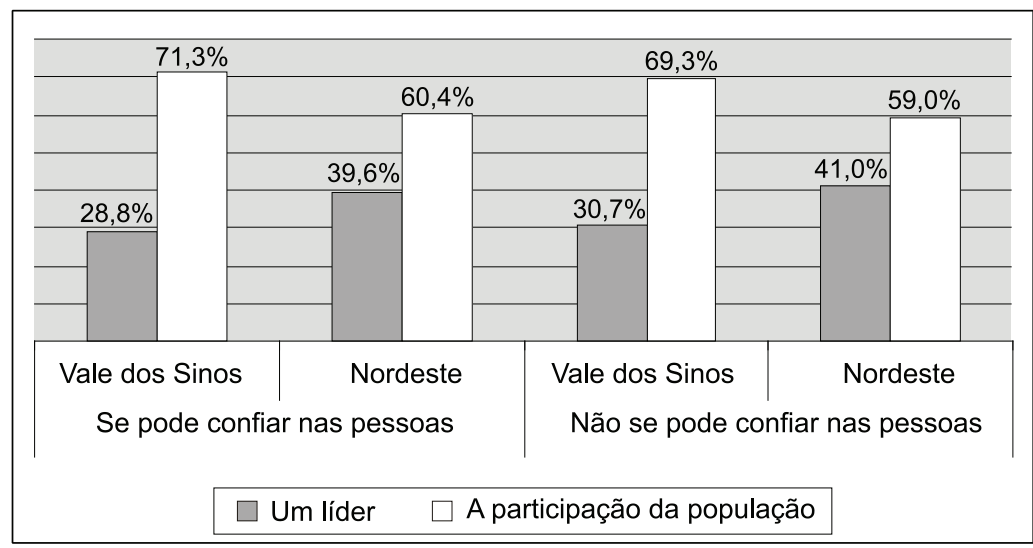

Fonte: Grupo de Pesquisa em Desenvolvimento Regional CPP/Feevale e Projeto de Pesquisa Capital Social e Desenvolvimento Territorial do Corede Nordeste. Total: Vale dos Sinos $\mathrm{N}=600$ - Nordeste $\mathrm{N}=606$.

Quando as pessoas não confiam umas nas outras, este percentual (da aposta no líder) sobe para 30,7\%. No Nordeste repete-se o fenômeno, do total dos pesquisados que disseram confiar nas pessoas 39,6\% afirmaram que "um líder seria necessário para resolver os problemas do país" e 60,4\% concordaram que "o melhor seria a participação popular"; quando cai a confiança temos $41,0 \%$ e $59,0 \%$, respectivamente. Ou seja, quanto menos confiança temse nas pessoas, mais facilmente se aposta em "saídas delegativas". Quando, ao contrário, a confiança aumenta, igualmente aumenta o percentual de apostas na participação popular.

Todavia, uma questão permanece: Há associação entre capital social (confiança interpessoal) e participação social e política? Aplicando-se o teste de Chi-quadrado (chi-square tests), para verificar se existe associação entre essas variáveis.

Inicialmente, o teste de Chi-quadrado foi realizado cruzando a questão sobre confiança interpessoal: em termos gerais, você diria que se pode confiar nas pessoas ou que não se pode confiar nas pessoas? Com questões sobre participação e associativismo 9

9 Foram apenas consideradas as pessoas que responderam participar em algumas dessas atividades. 
em: partidos políticos, reuniões políticas, comícios, associações comunitárias, associações religiosas, associações sindicais, conselhos populares, organizações não-governamentais, orçamento participativo, abaixo assinado, manifestações ou protestos, greves, ocupação de terrenos e se o entrevistado participa de ações que visem resolver algum problema do bairro ou comunidade.

Na região do Vale dos Sinos o teste mostrou-se significativo, ou seja, apresentou associação forte ${ }^{10}$ para participação em abaixo assinados $(0,010)$ e associação marginalmente significativa para participação em manifestos $(0,054)$, associações comunitárias $(0,067)$ e participação no auxílio de problemas do bairro e/ou da comunidade $(0,079)$. Ou seja, a confiança nas pessoas guarda uma certa relação de associação às formas de participação e associação no Vale do Sinos.

Já na análise dos dados da região Nordeste do estado, o resultado do teste apresentou um maior número de associações fortes entre confiança interpessoal e participação. A associação mais significativa foi observada em relação à participação em organizações não governamentais $(0,001)$ e no orçamento participativo $(0,024)$, seguida de associação marginalmente significativa pela participação em associações comunitárias $(0,007)$ e conselhos populares $(0,09)$. Em suma, a região Nordeste apresentou maiores indicadores de participação em atividades políticas (diretas e indiretas) do que a região do Vale dos Sinos. Assim, percebe-se na região Nordeste do estado que as formas de participação estão mais associadas a confiança interpessoal, ou seja, ao capital social.

\section{Considerações Finais}

Este artigo procurou demonstrar por meio de evidências empíricas em duas regiões investigadas no Rio Grande do Sul (Corede Vale do Rio dos Sinos e Corede Nordeste) a hipótese clássica de Putnam (2000), de que existe associação entre capital social e democracia. Demonstramos que a existência de estoques de capital

10 Resultado do teste próximo a 0,00 . 
social em uma determinada sociedade, como confiança interpessoal (trust), influencia positivamente na crença no regime democrático e em suas instituições. Sabemos que, muito embora não tenhamos explorado o total do arsenal de dados que as pesquisas aqui utilizadas ${ }^{11}$ disponibilizavam (e que podem ser mais bem explorados oportunamente), sobre a participação societal e suas relações com o capital social, alguns apontamentos podem ser feitos.

Primeiro, os dados revelam que a confiança interpessoal que se estabelece em determinada configuração societal está diretamente relacionada à crença que estas populações nutrem por suas instituições e pode ser mais fortemente associada às questões democráticas. Condições sociais que favorecem o capital social levam ao apoio destas populações às instituições democráticas. Estas evidências ficaram demonstradas na análise das tabelas tanto na região do Corede Nordeste, quanto no Corede do Vale do Rio dos Sinos. Contudo, de maneira mais "fraca" no Corede do Vale do Rio dos Sinos e de maneira mais "significativa" no Corede Nordeste. Segundo, a partir de uma análise preliminar dos dados, corroboramos a hipótese de que há associação entre os componentes que formam o capital social e democracia e que estas associações combinam-se de diferentes formas nas regiões estudadas.

Particularmente, no Corede Nordeste há uma maior concentração de capital social do que no Corede do Vale do Rio dos Sinos; desta forma, também há uma maior satisfação com o funcionamento da democracia lá do que no Vale do Rio dos Sinos. Todavia, muito embora tenhamos demonstrado os efeitos que o capital social causa nas diferentes regiões, é desafio maior pensarmos nas possibilidades apresentadas nestas configurações societais para melhorarmos as dotações locais de capital social, bem como nos obstáculos postos a esta tarefa.

Recebido em 7 de março de 2008 Aprovado em 10 de junho de 2008

11 Grupo de Pesquisa em Desenvolvimento Regional CPP/Feevale e Projeto de Pesquisa Capital Social e Desenvolvimento Territorial do Corede Nordeste 


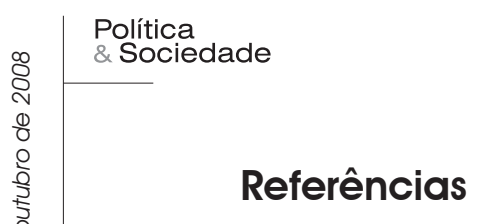

BAQUERO, M. Partidos e cultura política na América Latina: uma combinação de instabilidade política? In.: BAQUERO, M. (Org). Desafios da democratização na América Latina. Debates sobre cultura política. Porto Alegre: UFRGS/La Salle, 1999.

. Sem confiança a democracia se torna inerte. É o capital social uma resposta? Um estudo sobre a América Latina. Revista Educação Unisinos. São Leopoldo, v. 9, n. 2, maio/agosto, 2005.

BORBA, J. Comportamento político e capital social na América Latina. Revista Debates. Porto Alegre: UFRGS, 2005.

CAROTHERS, T. The end of the transition Paradigm. Jornal of Democracy. Johns Hopkins University and the National Endowment for Democracy, 2002.

DAHL, R. Polyarchy, participation and position. New Haven: Yale University, 1971.

EASTON, D. Uma teoria de análise política. Rio de Janeiro: Zahar, 1968.

HUNTIGTON, S. A terceira onda: democratização no final do século XX. São Paulo: Ática, 1994.

LAMONIER, B. Perspectivas da consolidação democrática o caso brasileiro. Revista Brasileira de Ciências Sociais. São Paulo: USP, 2005.

MAINWARING, S. Transitions to Democracy and democratic consolidation: theoretical and comparative Issues. In: MAINWARING, S; O'DONNELL, G. \& VALENZUELA, S. (org.). Issues in democratic consolidation: the New South American Democracies in comparative Pespective. Notre Dame: University of Notre Dame, 1992.

MATTA, R. O que faz o Brasil, Brasil? Rio de Janeiro: Rocco, 2001. MOISÉS, J. Os Brasileiros e a democracia. São Paulo: Ática, 1995.

NUN, J. La Democracia y la modernizacion: treinta años después. In.: SIERRA, G. (org). Democracia emergente en América del Sur. Ciudade del México: UNAM, 1994.

O’DONNELL, G \& SCHMITTER, P. Autoritarismo e democratização. São Paulo: Vértice, 1986. 
O’DONNELL, G \& SCHMITTER, P. Transições do regime autoritário. São Paulo: Vértice, 1988.

PASE, H. Capital social e desenvolvimento rural no Rio Grande do Sul. Tese (Doutorado em Ciência Política) - UFRGS: Porto Alegre, 2006.

PUTNAM, R. Bowling alone: America's declining Social Capital. In.: DIAMOND, L. \& PLATTNER, M. (org.). The global resurgence of Democracy. Baltimore and London: Johns Hopkins University, 1996.

PUTNAM, R. Comunidade e Democracia. A experiência da Itália Moderna. Rio de Janeiro: FGV, 2000.

STEPAN, A. \& LINZ, J. A transição e consolidação da Democracia. A experiência do sul da Europa e da América do Sul. São Paulo: Paz e Terra, 1999.

VERBA, S. \& ALMOND, G. The civic Culture. Political attitudes and Democracy in five Nations. Newbury Park, 1989. 
